\section{$\begin{array}{lllllllllll}\mathbf{R} & \mathbf{E} & \mathbf{P} & \mathbf{E} & \mathbf{R} & \mathbf{T} & \mathbf{O} & \mathbf{R} & \mathbf{I} & \mathbf{O}\end{array}$}

Segunda nueva época № 29, Enero-Diciembre, 2019

\title{
Espacios de Afecto
}

\author{
Diego Zamora-Cascante \\ Investigador independiente
}

$\mathbf{M}$ uestra de artes visuales de la artista Karina Siliézar Delgado, realizada en el Vestíbulo de la Vicerrectoría de Acción Social de la Universidad de Costa Rica, agosto 2019.

Preocupada por el desapego afectivo, la falta de comunicación y el contacto humano, Karina Siliézar Delgado nos muestra en esta primera exposición individual una serie de trabajos donde el afecto por medio del abrazo toma protagonismo para interpelarnos sobre los espacios y límites en la intimidad de lo cotidiano.

Este conjunto de dibujos toma como punto de partida sus vivencias, así como las vivencias de personas cercanas cuya preocupación radica en la frialdad y la distracción ontológica de este mundo globalizado. Sin embargo, para la artista la distracción funciona como una herramienta en la que se cuestiona deteniéndose a observar los constantes estímulos a los que estamos expuestos.
Por medio de la simpleza de la línea en su trabajo, nos lleva a relacionarnos mediante el juego de imagen-palabra con todo lo que nos rodea, intimando con las representaciones, evocando experiencias vividas u observadas en algún momento de nuestra vida.

Abrazar es la acción de rodear con nuestros brazos y puede tener múltiples significados. Por medio de esta acción se puede demostrar ternura, inocencia o pasión; aunque también se puede comunicar, transmitir sensaciones o sentimientos de quienes estén involucrados.

En esta muestra, Karina nos invita a cuestionarnos desde nuestra experiencia de vida los espacios de afecto e intimidad y sus límites, directamente nos cuestiona cuáles o cuántas maneras conocemos para abrazarnos o para abrazar lo que nos rodea: seres humanos, naturaleza u objetos cuyo significado trasciende. 


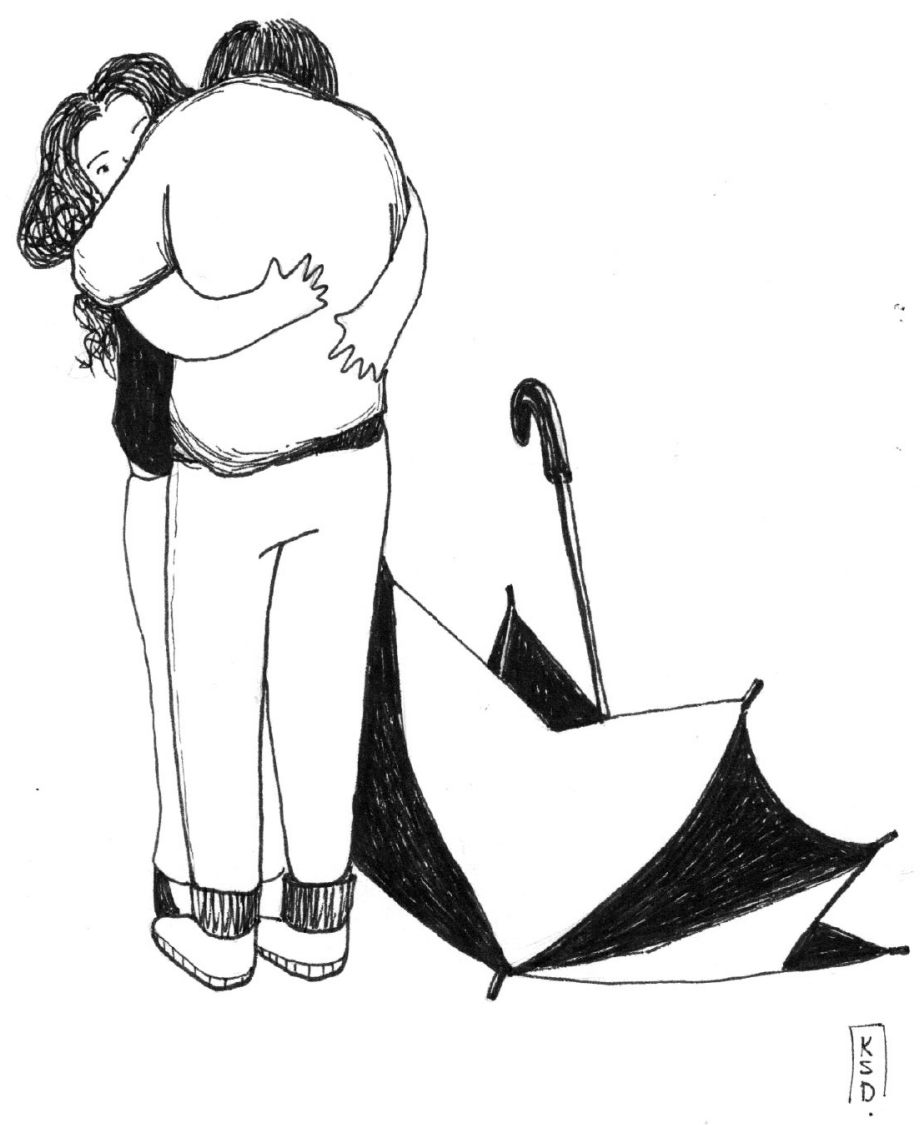

- el abozo que en realidad es beso-

Abrazo que en realidad es beso.

Plumilla

$17,5 \times 25 \mathrm{~cm}$. 


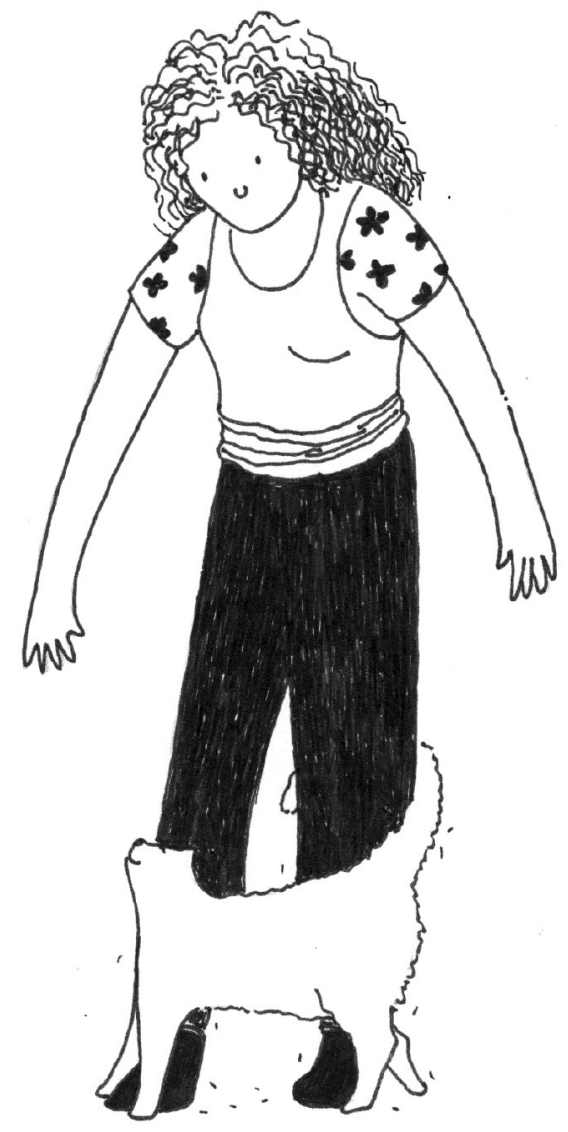

- abrazu de seir patas.

Abrazo de seis patas.

Plumilla

$25 \times 17,5 \mathrm{~cm}$. 


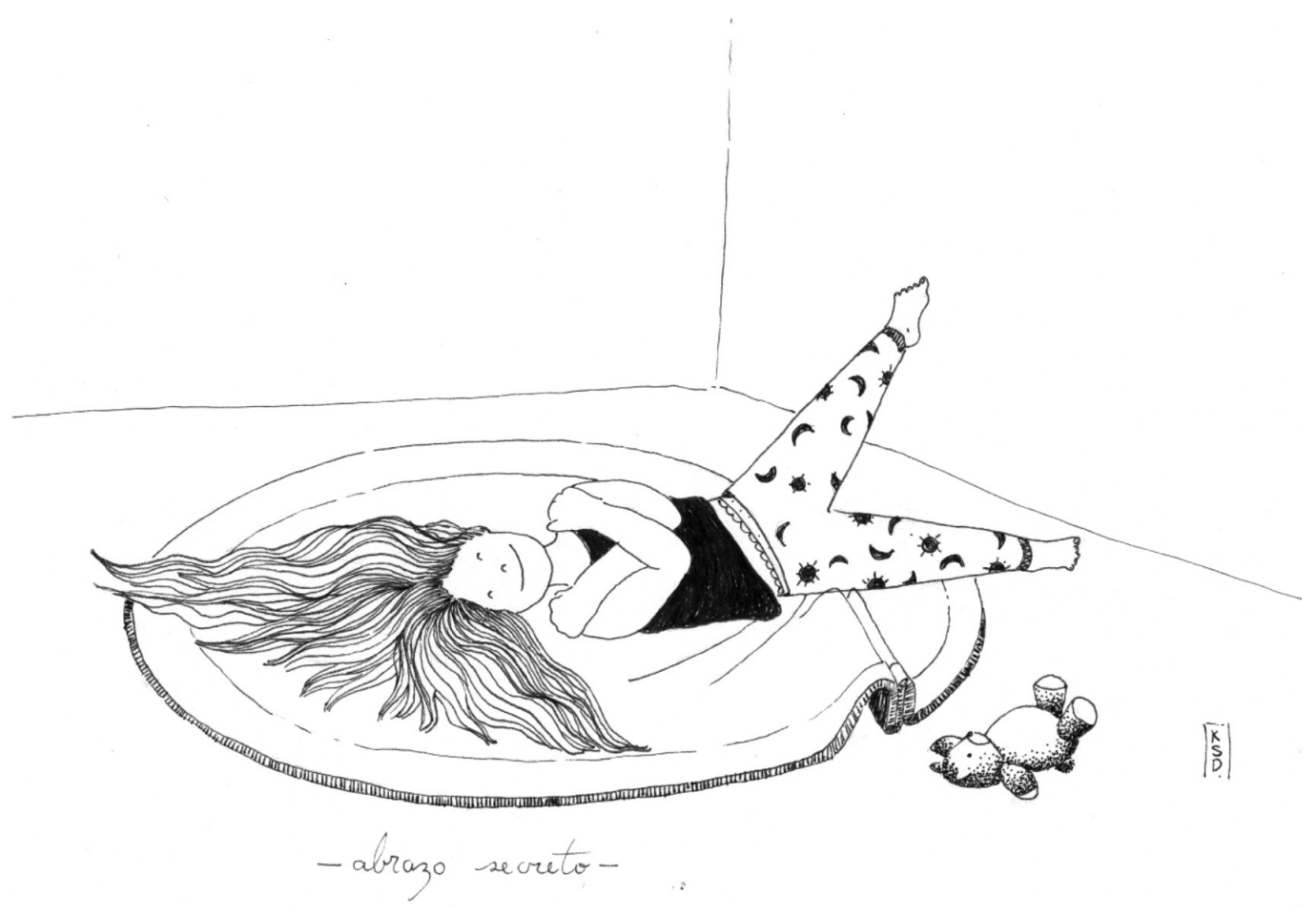

Abrazo secreto.

Plumilla

$17,5 \times 25 \mathrm{~cm}$. 


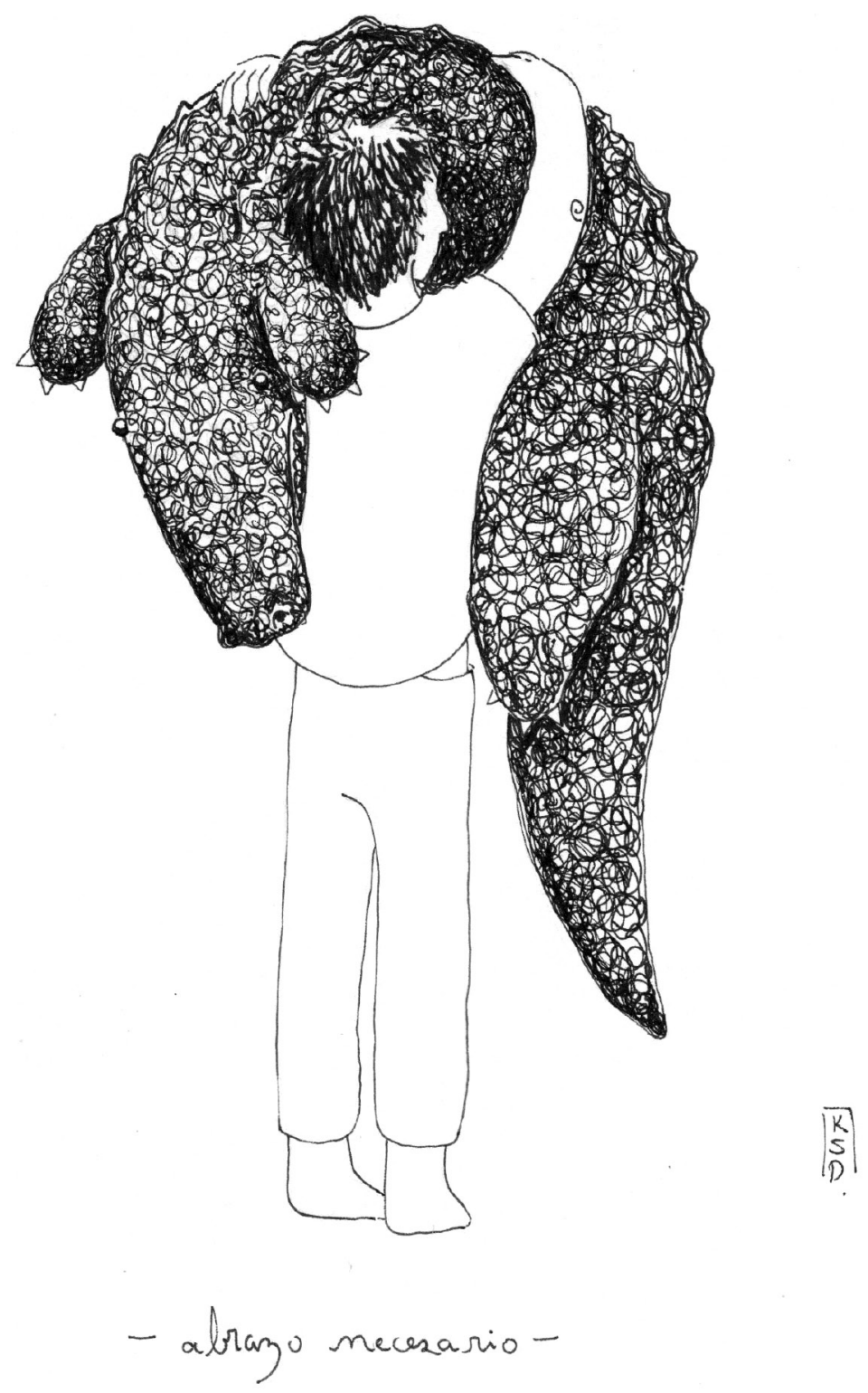

Abrazo necesario.

Plumilla

$25 \times 17,5 \mathrm{~cm}$. 


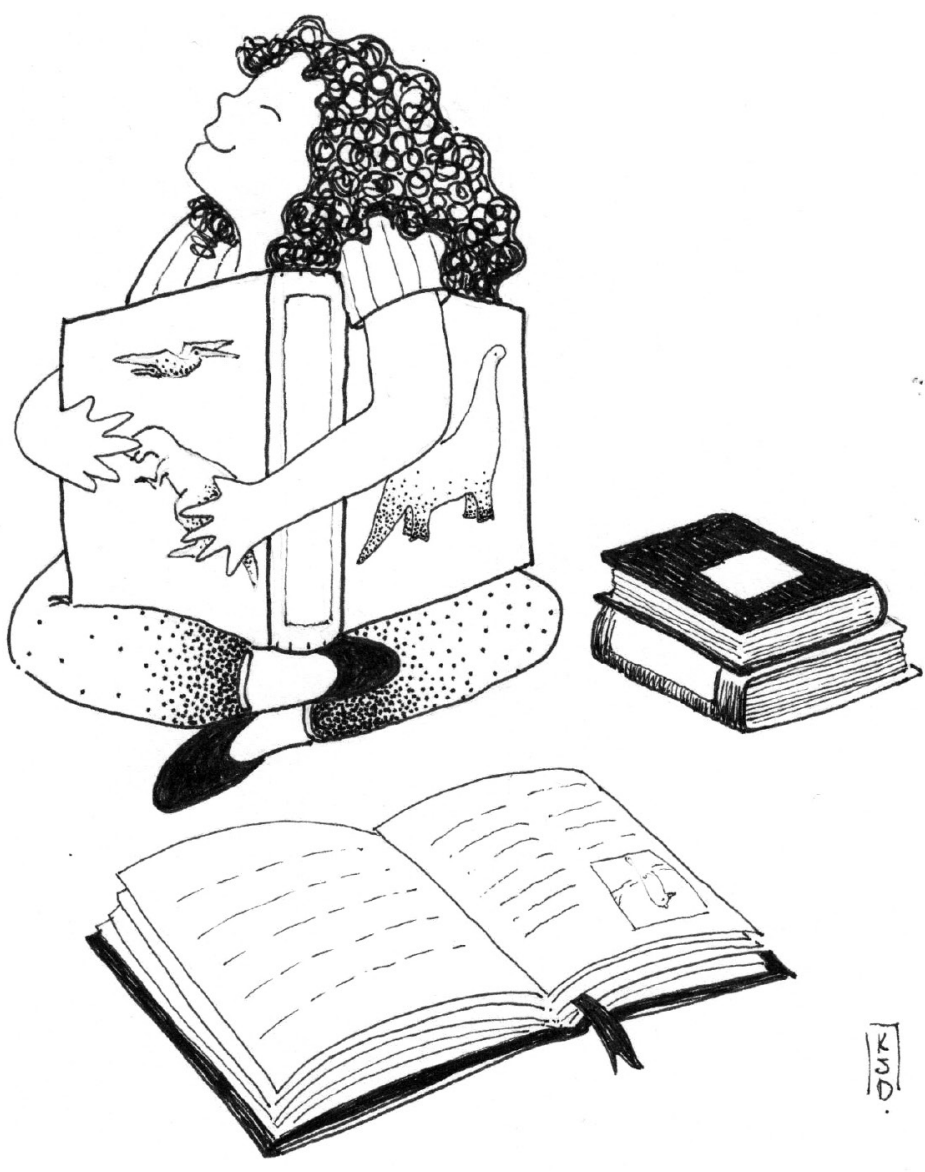

- abrazo de papel-

Abrazo de papel.

Plumilla

$25 \times 17.5 \mathrm{~cm}$. 